\title{
DISSEMINATED SUPERFICIAL ACTINIC POROKERATOSIS, BOWEN'S DISEASE AND BASAL CELL CARCINOMA. COINCIDENCE OR RARE DOUBLE MALIGNANT TRANSFORMATION?
}

\author{
Todor Yordanov ${ }^{1}$, Elisaveta Popchristova ${ }^{1}$, Neli Koleva ${ }^{1}$, Irina Yungareva ${ }^{1}$, \\ Jenya Dimitrova ${ }^{2}$, Sonya Marina ${ }^{1}$ \\ ${ }^{1}$ Department of Skin and Venereal Diseases, Medical Institute of the Ministry \\ of Internal Affairs \\ ${ }^{2}$ Department of Infectious Diseases, Parasitology and Dermatovenereology, \\ Faculty of Medicine, Medical University of Varna
}

\begin{abstract}
Disseminated superficial actinic porokeratosis (DSAP) is a skin condition that consist of multiple annular, hyperkeratotic lesions. They are usually distributed bilaterally and mostly affect the extremities. DSAPs have a wider distribution than the porokeratosis of Mibelli and usually appears between the age of 40 and 50. Squamous cell carcinoma, Bowen's disease, and basal cell carcinoma that arises in the classical type of porokeratosis of Mibelli is well-documented, but there are not many reported cases of Bowen's disease and basal cell carcinoma arising in DSAP. We present a 77-year-old woman in whom the two- Bowen's disease and Basal cell carcinoma develop in a histologically proven DSAP.
\end{abstract}

Keywords: disseminated superficial actinic porokeratosis, squamous cell carcinoma, Bowen's disease, basal cell carcinoma

\section{INTRODUCTION}

Porokeratosis is a keratinization abnormality, presenting with atrophic patches surrounded by a clinically and histologically distinctive hyperkeratotic border called the cornoid lamella. Historically, the term porokeratosis was coined on the assumptions that cornoid lamellae appear from pores of the sweat glands (1). Cornoid lamellation expands peripherally and forms the raised boundary between normal

\footnotetext{
Address for correspondence:

Jenya Dimitrova

Faculty of Medicine

Medical University of Varna

55 Marin Drinov St

9002 Varna

e-mail:dimitrova_derm@abv.bg
}

Received: January 22, 2020

Accepted: March 18, 2020 and abnormal keratinocytes, showing disturbed differentiation but no increase in the rate of proliferation $(2,3)$.

Multiple clinical variants of porokeratosis are recognized: classic porokeratosis of Mibelli (PM) (4); disseminated superficial actinic porokeratosis (DSAP) and its non-actinic variant disseminated superficial porokeratosis (DSP); linear porokeratosis; porokeratosis palmaris et plantaris disseminata and punctate porokeratosis, which is thought to be a variant of the previous form.

DSAP is the most common subtype of porokeratosis (5). This is an autosomal dominant condition with a typical lesion - annular, hyperkeratotic, brown or brownish macules and papules. The center of the lesions is atrophic and the border spreads centrifugally in raised ridges. Lesions almost always affect sun-exposed areas $(5,6)$. 
Todor Yordanov, Elisaveta Popchristova, Neli Koleva et al.

Malignancies, typically squamous cell carcinomas, may develop within lesions of porokeratosis in about $7.5 \%$ of patients $(7,8,9)$.

\section{CASE REPORT}

A 77-year-old female presented to our department in 2016 with skin lesions on both lower extremities. Although the skin findings had long duration, in the past two years they increased significantly in number. Subjectively, the patient found the lesions pruritic. The objective findings were typical for porokeratosis - annular, hyperkeratotic, brownish papules on both shins. Biopsy was performed and specimen was taken from two skin lesions. The diagnostic features of disseminated superficial actinic porokeratosis were present: a cornoidlamella - parakeratotic column overlying a small vertical zone of dyskeratotic cells within the epidermis and focal loss of the granular layer. After histological confirmation of the diagnosis, a systemic treatment with Acitretin was initiated - 3 tablets a day for a 3-month period.

On a follow-up visit 4 years later, the patient showed good therapeutic result on both of her lower extremities. Nevertheless, there were two slowly growing lesions - one on the left shin and the other in the right gluteal region.

On physical examination the lesion on the left lower extremity presented as solitary, erythematous, irregular, scaly, crusted plaque, with irregular borders and a diameter of $40 \mathrm{~mm}$ (Fig. 1).

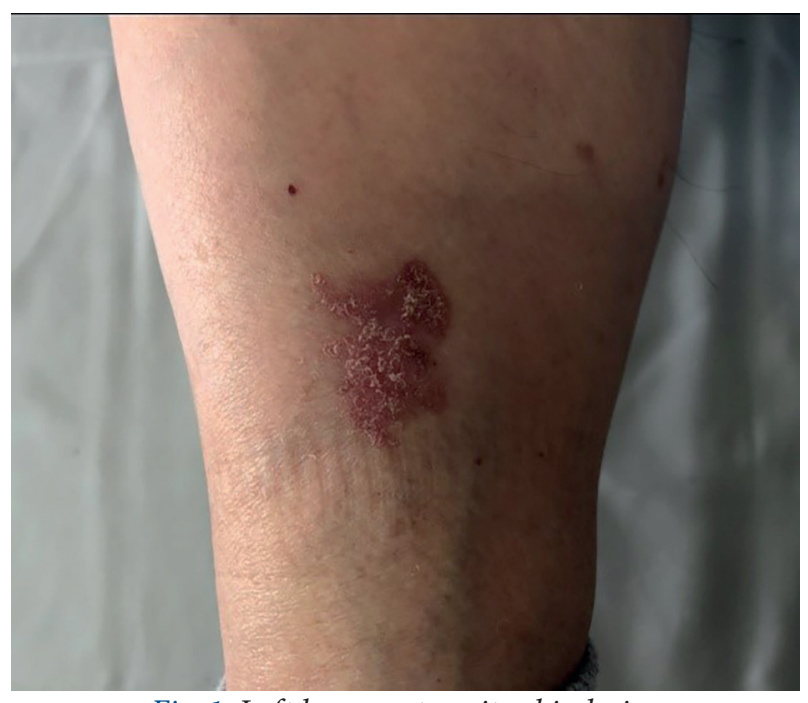

Fig. 1. Left lower extremity skin lesion
In the right gluteal region, a solitary, erythematous plaque with a diameter of $10 \mathrm{~mm}$ was observed, characterized by telangiectasias on the periphery of the lesion (Fig. 2).

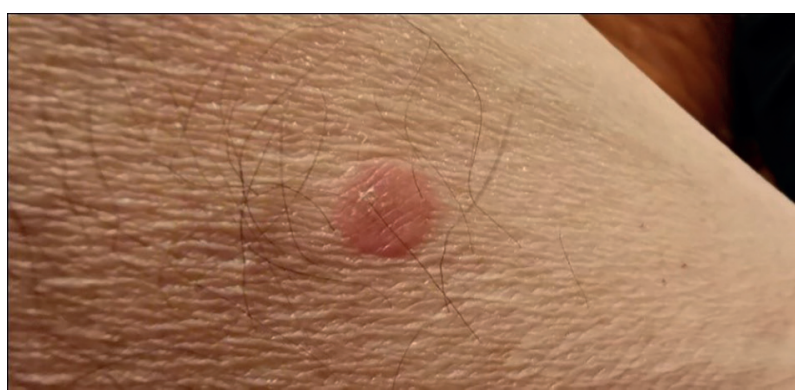

Fig. 2. Right gluteal skin lesion

Skin biopsy was taken from the left lower extremity lesion. The gluteal plaque was excised totally with $5 \mathrm{~mm}$ surgical margins.

Histopathology examination of the specimen obtained from the erythematous plaque on the left shin showed: clonal island of atypical keratinocytes within the epidermis. Glassy, eosinophilic cells. Focally presented buckshot scatter. Apoptotic keratinocytes scattered within nests. Compact and parakeratotic overlying stratum corneum. The pathological diagnosis was squamous cell carcinoma in situ (SCCIS, Bowen's disease) (Fig. 3).

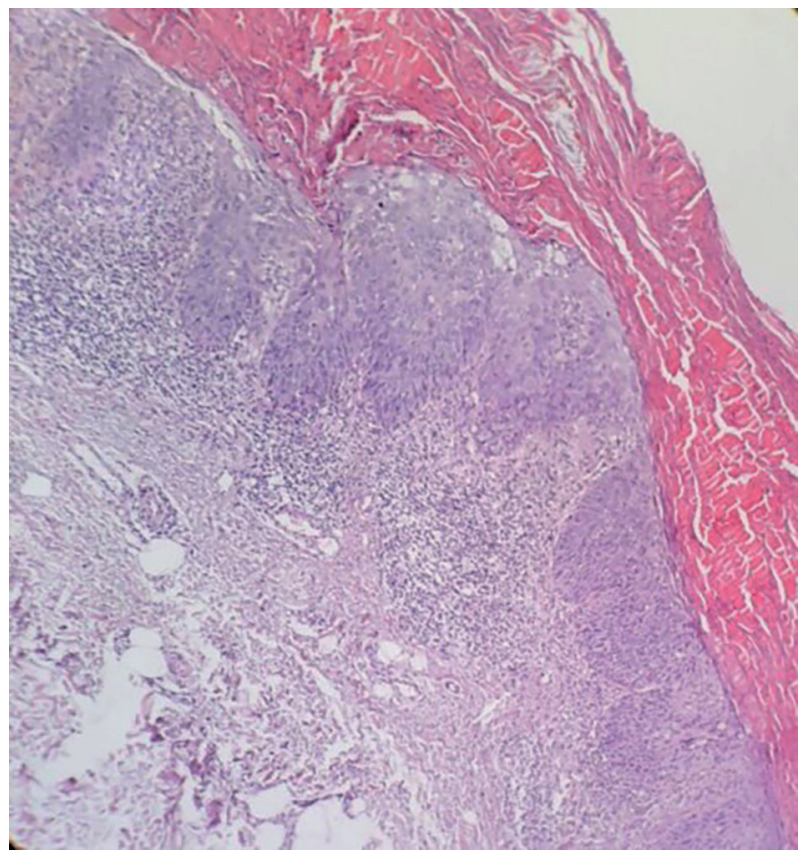

Fig.3. Histological findings of lower extremity skin lesion 
Disseminated Superficial Actinic Porokeratosis, Bowen’s Disease and Basal Cell Carcinoma. Coincidence or Rare Double Malignant...

Histopathology examination of the lesion from the right gluteal region showed: basaloid epithelial tumour arising from the epidermis. The basaloid epithelium formed a palisade with a cleft from the adjacent tumor stroma. Centrally, the nuclei were crowded with scattered mitotic figures and necrotic bodies. Mucinous stroma was seen. The diagnosis of superficial basal cell carcinoma was histologically confirmed (Fig. 4).

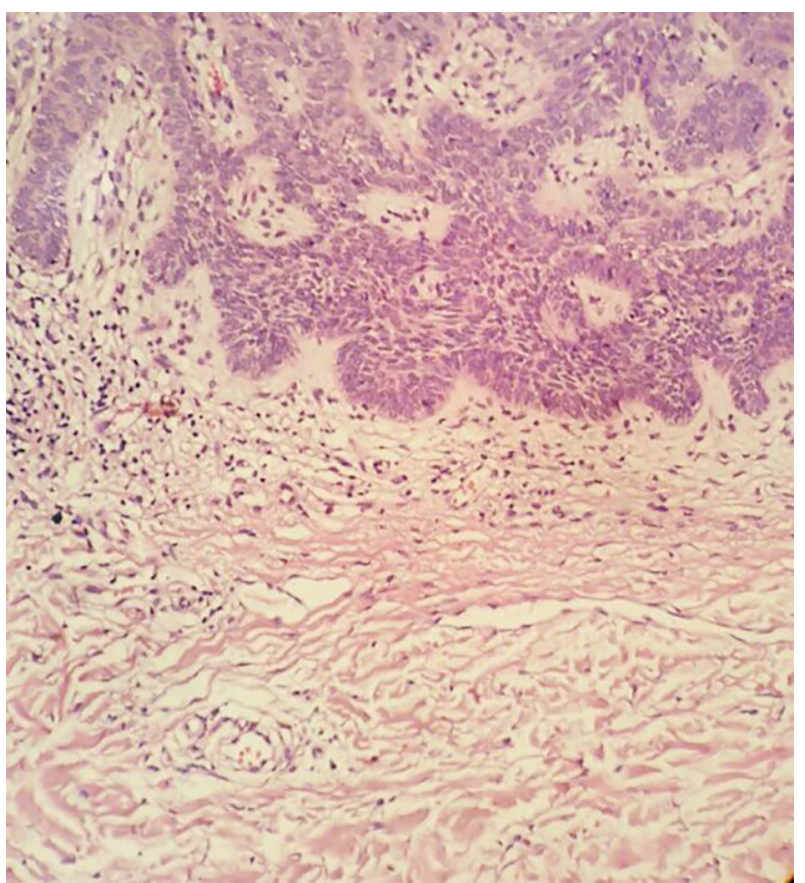

Fig. 4. Histological findings of gluteal skin lesion

As the margins of the specimen were clear, the patient was considered cured from the basal cell carcinoma. Nevertheless, the next operation for the treatment of the SCCIS lesion was planned.

\section{DISCUSSION}

DSAP is the most common form of porokeratosis, and may account for almost half of all cases (10). Porokeratosis most commonly occurs in fairskinned individuals. DSAP is twice as likely to develop in women compared to men (11). DSAP affect all ages, but occurs mainly in the $3^{\text {rd }}$ and $4^{\text {th }}$ decade.

Typically, the lesions affect sun-exposed areas, predominantly upper and lower extremities. Patients develop a few to several dozen pigmented, annular macules with raised peripheral ridges, devel- oping predominantly on the distal extensor surfaces of the legs and the arms. Palms and soles are spared, and facial lesions may be seen in less than $15 \%$ of patients. Hyperkeratotic variants have been described. The lesions are usually asymptomatic, but they may be itchy or slightly stinging (12).

The pathogenesis of DSAP is not fully understood, but overexpression of p53 is described $(13,14)$. This can be induced by several factors, like UV light, gene mutations, DNA damaging agents and others $(8,15,16)$.

Exacerbations have been reported following prolonged sun exposure, repeated tanning bed exposure, electron beam radiation therapy, and therapeutic phototherapy or photochemotherapy for psoriasis. Drug-induced photosensitivity may play a role. Protection from ultraviolet radiation may lead to spontaneous resolution. Additionally, immunosuppression predisposes patients to both DSAP and DSP.

The differential diagnoses are: actinic keratoses, pityriasis lichenoides chronica, and chronic eczema. The characteristic histopathology findings usually confirm the diagnosis.

The prognosis is generally excellent. The occurrence of some types of pre-malignancies or malignancies proves the pre-cancerous nature of this condition. Malignancies have been reported for the porokeratosis of Mibelli, linear porokeratosis, porokeratosis palmaris et plantaris, and DSAP. Associated malignancies are BCC, SCC, Bowen's disease $(8,16,17)$. There are many case reports of these types of malignancy arising from some kind of porokeratosis (13). In most cases neoplasms appear on the extremities. That proves the role of UV rays in malignant transformation of DSAP lesions $(13,18)$. Large lesions of porokeratosis, linear porokeratosis, or porokeratosis in an immunocompromised patient should be monitored carefully for the development of cutaneous malignancies (19).

Patients should be advised to practice strict sun protection. The measures include wearing protective clothing, applying sunscreens and discontinuing exposure to artificial ultraviolet light. The skin of the individuals with DSAP should be periodically examined for lesions suggestive of malignancy. If familial porokeratosis is suspected, family members should also be examined for porokeratosis. 
Todor Yordanov, Elisaveta Popchristova, Neli Koleva et al.

Aesthetic results from the treatment of DSAP lesions are usually unsatisfactory. Nevertheless, malignant transformation of skin lesions should be expected and promptly treated as our case also showed.

\section{REFERENCES}

1. Biswas A. Cornoid lamellation revisited: apropos of porokeratosis with emphasis on unusual clinicopathological variants. Am J Dermatopathol. 2015;37(2):145-55. doi: 10.1097/ DAD.0000000000000039.

2. Fernandez-Flores A. Small lesions of porokeratosis show a normal proliferation rate with MIB1. Acta Dermatovenerol Alp Pannonica Adriat. 2008;17(1):22-5.

3. Kamata Y, Maejima H, Watarai A, Saito N, Katsuoka K, Takeda A, et al. Expression of bleomycin hydrolase in keratinization disorders. Arch Dermatol Res. 2012 ;304(1):31-8. doi: 10.1007/ s00403-011-1180-6.

4. Ma Y, Li C, Wu J, Cui P, Lin L, Feng S. Coexistence of porokeratosis ptychotropica with porokeratosis of Mibelli in a Chinese man. Postepy Dermatol Alergol. 2015;32 (4):307-9. doi: 10.5114/ pdia.2015.53324.

5. Shumack SP, Commens CA. Disseminated superficial actinic porokeratosis: a clinical study. J Am Acad Dermatol. 1989;20(6):1015-22. doi: 10.1016/ s0190-9622(89)70126-2.

6. Yang HY, Nam TS, Kim YT, Kim JH. A case of squamous cell carcinoma and Bowen's disease associated with superficial disseminated porokeratosis. Ann Dermatol. 1990; 2:31-4.

7. James WD, Rodman OG. Squamous cell carcinoma arising in porokeratosis of Mibelli. Int J Dermatol. 1986;25(6):389-91. doi: 10.1111/j.1365-4362.1986. tb03430.x.

8. Sasson M, Krain AD. Porokeratosis and cutaneous malignancy. A review. Dermatol Surg. 1996;22(4):339-42. doi: 10.1111/j.1524-4725.1996. tb00327.x.

9. Seishima M, Izumi T, Oyama Z, Maeda M. Squamous cell carcinoma arising from lesions of porokeratosis palmaris et plantaris disseminata. Eur J Dermatol. 2000;10(6):478-80.
10. Leow YH, Soon YH, Tham SN. A report of 31 cases of porokeratosis at the National Skin Centre. Ann Acad Med Singapore.1996;25(6):837-41.

11. Sertznig P, von Felbert V, Megahed M. Porokeratosis: present concepts. J Eur Acad Dermatol Venereol. 2012;26(4):404-12. doi: 10.1111/j.1468-3083.2011.04275.x.

12. Jang KA,Choi JH, Sung KJ, Moon KC, Koh JK.. The hyperkeratotic variant of disseminated superficial actinic porokeratosis (DSAP). Int J Dermatol.1999;38(3):204-6. doi: 10.1046/j.1365-4362.1999.00657.x.

13. Ninomiya $Y$, Urano $Y$, Yoshimoto $K$, Iwahana $\mathrm{H}$, Sasaki S, Arase S, et al. p53 gene mutation analysis in porokeratosis and porokeratosis-associated squamous cell carcinoma. J Dermatol Sci. 1997;14(3):173-8. doi: 10.1016/ s0923-1811(96)00569-5.

14. Magee JW, McCalmont TH, Leboit PE. Overexpression of $\mathrm{p} 53$ tumor suppressor protein in porokeratosis. Arch Dermatol. 1994;130(2):187-90.

15. Lozinski AZ, Fisher BK, Walter JB, Fitzpatrick PJ. Metastatic squamous cell carcinoma in linear porokeratosis of Mibelli. J Am Acad Dermatol. 1987;16(2 Pt 2):448-51. doi: 10.1016/s0190-9622(87)70059-0.

16. Taylor AM, Hamden DG, Fairburn EA. Chromosomal instability associated with susceptibility to malignant disease in patients with porokeratosis of Mibelli. J Natl Cancer Inst. 1973;51(2):371-8.

17. Maubec E, Duvillard P, Margulis A, Bachollet B, Degois G, Avril MF. Common skin cancers in porokeratosis. Br J Dermatol. 2005;152(6):1389-91. doi: 10.1111/j.1365-2133.2005.06639.x.

18. Leache A, Soto de Delás J, Vázquez Doval J, Lozano MD, Quintanilla E. Squamous cell carcinoma arising from a lesion of disseminated superficial actinic porokeratosis. Clin Exp Dermatol. 1991;16(6):4602. doi: 10.1111/j.1365-2230.1991.tb01237.x.

19. Otsuka F, Umebayashi Y, Watanabe $S$, Kawashima M, Hamanaka S. Porokeratosis large skin lesions are susceptible to skin cancer development: histological and cytological explanation for the susceptibility. J Cancer Res Clin Oncol. 1993;119(7):395400. doi: 10.1007/BF01218420. 